\title{
POLÍTICAS DE INCLUSÃO NA EDUCAÇÃO BÁSICA DO MUNICÍPIO DE VALENÇA-BAHIA
}

POLICIES FOR INCLUSION IN BASIC EDUCATION IN THE CITY OF VALENÇABAHIA

\author{
Viviane Alves da Silva Santos \\ Pedagoga Especialista, IFMG - Campus Arcos, Brasil \\ E-mail: vivishow10@yahoo.com.br \\ ORCID: https://orcid.org/0000-0002-3199-033X \\ Marcela de Melo Fernandes \\ Doutoranda em Ensino, IFMG Campus Arcos, Brasil \\ e-mail: marcela.fernandes@ifmg.edu.br \\ ORCID: https://orcid.org/0000-0002-4144-3380
}

Recebido: 06/01/2021 - Aceito: 08/02/2021

\section{Resumo}

Introdução: Quando se fala em Educação Inclusiva, nos remete a Educação voltada para pessoas com deficiência, todavia, ela não está atrelada apenas a essa questão, mas também na oportunidade de inclusão para todos aqueles que tiveram seus direitos violados. Objetivo: Analisar as políticas de inclusão na Educação básica do município de Valença-Ba e também em âmbito das leis federais. Metodologia: A investigação tratou-se de um estudo descritivo e exploratório com abordagem qualitativa de cunho bibliográfico e documental dos principais documentos municipais e Federais sobre as políticas de Inclusão escolar. Analise dos dados: Foi realizado um estudo das leis federais e do município de Valença-Ba acerca da política de inclusão e feita uma categorização dos dados sobre a leis que asseguram a inclusão no município. Conclusão: que o município de Valença-BA enfrenta desafios no que se refere a efetividade das políticas de inclusão educacional, todavia, verifica-se que o Munícipio tem evoluído, ainda que de forma gradual no cumprimento e manutenção das normativas educacionais preconizadas na Constituição Federal de 1988, na LDBN lei no 9394/96 e os demais documentos normativos em âmbitos Federais, Estaduais e Municipais.

Palavras-chave: Educação; Inclusão; Políticas públicas. 


\section{Abstract}

Introduction: When it comes to Inclusive Education, Education refers to people with disabilities, however, it is not linked only to this issue, but also in the opportunity of inclusion for all those who have had their rights violated. Objective: To analyze the policies for inclusion in basic education in the municipality of Valença-Ba and also within the scope of federal laws. Methodology: The investigation is a descriptive and exploratory study with a qualitative approach of bibliographic and documentary nature of the main municipal and federal documents on school inclusion policies. Analysis of the data: A study of federal and municipal laws in Valença-Ba about the inclusion policy and a categorization of the data about the laws that ensure inclusion in the municipality. Conclusion: that the municipality of Valença-BA faces challenges with regard to the effectiveness of educational inclusion policies, however, it appears that the Municipality has evolved, albeit gradually in the fulfillment and maintenance of the educational norms recommended in the Federal Constitution of 1988, in LDBN law no 9394/96 and the other normative documents at Federal, State and Municipal levels.

Keywords: Education; Inclusion; Public policy.

\section{Introdução}

Quando se fala em Educação Inclusiva, nos remete a Educação voltada para pessoas com deficiência, todavia, ela não está atrelada apenas a essa questão, mas também na oportunidade de inclusão para todos aqueles que tiveram seus direitos violados.

A política de inclusão brasileira com enfoque na equiparação é recente, tendo seu marco a promulgação da Constituição Federal (1988), mais conhecida como Constituição cidadã, por seu conteúdo definir que todo brasileiro tem direito a Educação, saúde, segurança e equiparação de oportunidade, enfim, a ampla garantia de direitos fundamentais.

Em se falando de garantia a Educação, o artigo 205 da Constituição define que a Educação é um direito de todos, que garante o pleno desenvolvimento da pessoa, o exercício da cidadania e a qualificação para o trabalho. E estabelece ainda que a igualdade de condições de acesso e permanência na escola é um princípio que deve ser respeitado e garantido (BRASIL, 1988).

Discutir sobre o direito à educação inclusiva para todos, considerando os principais marcos legais e teóricos que abalizam a defesa pela garantia de uma 
Revista Multidisciplinar do Nordeste Mineiro,

$2021 / 01$

ISSN 2178-6925

escolarização igualitária para as minorias como negros, indígenas, pessoas trans, com necessidades educacionais especiais (sindrome de down, surdos, cegos, autistas, entre outros), faz-se necessário tendo em vista o contexto políticoeducacional que se apresenta nos dias de hoje, sobretudo em relação às políticas públicas que tratam da Educação equiparadora de oportunidades, sinalizando os avanços (pontos) e retrocessos (contra-pontos) que permeiam a Educação Inclusiva e em que medida estas políticas educacionais garantem de fato o acesso e permanencia dessa população na escola.

Tendo em vista a política neoliberal atual, discorrer acerca do direito à educação para as minorias requer a revisão do conceito de democracia e sua articulação na forma como configura as políticas públicas educacionais no Brasil atualmente. Vale salientar que não se pode falar sobre equiparação de oportunidades e inclusão, sem incluir a questão da diversidade no tocante a afirmação da igualdade.

O tema Educação Inclusiva tem suscitado muitas discussões nos meios educacionais desde que essa proposta chegou ao Brasil, sobretudo nas perspectivas em torno das políticas públicas de inclusão. As políticas de inclusão têm como principal objetivo a oferta de Educação igualitária e de qualidade para todos, bem como o acesso e permanência no ensino regular em todas as etapas da Educação básica.

Vale destacar que quando se fala em acesso à Educação igualitária e de qualidade, estamos falando da afirmação dos direitos humanos em todas as esferas sociais, pois a educação é o caminho para romper com os paradigmas da exclusão. No tocante as políticas de inclusão, devemos nos atentar para a perspectiva de equiparação de oportunidades, tendo como princípio o reconhecimento das diferenças não como algo negativo, mas sim, saldando uma dívida histórica com as pessoas que tiveram seus direitos negados.

A inclusão que queremos deve pautar-se em um ensino destinado não apenas a um grupo exclusivo de alunos, o dos deficientes, mas especializada no aluno e dedicada à pesquisa e ao desenvolvimento de novas maneiras de se ensinar, adequadas à diversidade dos aprendizes e que estejam compatíveis com 
Revista Multidisciplinar do Nordeste Mineiro,

os ideais democráticos de uma educação para todos, promulgados pela nossa Constituição.

O objetivo deste estudo foi analisar as políticas de inclusão na Educação básica do município de Valença-Ba e também em âmbito das leis federais. Os objetivos específicos são: analisar os principais desafios do processo de inclusão em escolar regulares da cidade de Valença-Ba, buscando identificar as principais diretrizes que regulamentam a inclusão na Educação básica e apontar quais políticas tem sido efetivada.

Nesse sentido, este estudo se justifica, pois, ao analisar a evolução das discussões acerca da inclusão escolar na educação básica, observa-se que a partir do XX muitas ações foram empreendidas focando uma sociedade que garantisse a todos os povos a conquista da igualdade de direitos e o respeito à diversidade humana. A Escola como espaço de mudanças e de inclusão, deve estar preparada para fazer da inclusão uma realidade em seu cotidiano, visando uma sociedade inclusiva por meio da democratização do ensino.

Assim, espera-se que este estudo atraia a atenção para o tema e contribua para a descoberta de novos enfoques que supere as perspectivas e que contribua para uma Educação democrática, igualitária e de qualidade para todos. Além disso, nossas conclusões podem servir de base para outros estudos da área de Educação Inclusiva e políticas públicas educacionais.

\section{MATERIAL E MÉTODOS}

A investigação tratou-se de um estudo descritivo e exploratório com abordagem qualitativa de cunho bibliográfico e documental dos principais documentos municipais da cidade de Valença - BA e Federais sobre as políticas de Inclusão escolar. Os dados primários foram coletados a partir da pesquisa documental, que de acordo com Fonseca (2002), é semelhante a pesquisa bibliográfica, todavia, a pesquisa documental recorre a fontes mais diversificadas e dispersas, sem tratamento analítico, tais como: tabelas estatísticas, jornais, 
Revista Multidisciplinar do Nordeste Mineiro,

\section{1/01}

ISSN 2178-6925

revistas, relatórios, documentos oficiais, cartas, filmes, fotografias, pinturas, tapeçarias, relatórios de empresas, vídeos de programas de televisão, etc.

Os dados secundários foram coletados por meio de publicações de organizações governamentais e empresas privadas, livros e artigos com publicações no Scientific Electronic Library Online - SCIELO. Utilizando os seguintes descritores: políticas públicas educacionais; Educação Inclusiva; leis de inclusão escolar na educação básica.

Os Critérios de inclusão foram artigos completos em português com publicação nos últimos cinco anos compreendendo entre os anos 2015 - 2020 com exceção de documentos normativos com datas anteriores a 2015. Sendo excluídos artigos com equívocos metodológicos e que não atendiam à proposta do estudo, bem como trabalhos incompletos, sem data, ou carta ao leitor.

Os instrumentos utilizados para a coleta de dados foram o Google acadêmico; formulário digital. Os procedimentos realizados foram:

1. Levantamento dos artigos e documentos (leis e normas) respeitando os critérios de inclusão e exclusão;

2. Identificação das fontes científicas adequadas, capazes de fornecer a resposta ao problema proposto;

3. Seleção das obras de interesse;

4. Leitura fichamento e análise das informações levantadas

5. Tratamento e tabulação dos dados;

6. Elaboração redacional do trabalho com base nas informações levantadas.

A tabulação e à organização dos dados foram definidas com o suporte do programa Microsoft Office Excel 2010, com uso de gráficos e tabelas sendo analisados e discutidos à luz dos autores/especialistas selecionados.

\section{RESULTADOS E DISCUSSÃO}


Revista Multidisciplinar do Nordeste Mineiro,

\section{1/01}

ISSN 2178-6925

A pesquisa documental versou em analisar os principais documentos normativos do município, bem como das leis federais que respaldam as políticas públicas educacionais na cidade de Valença - Ba. Os principais documentos analisados foram tabulados na tabela abaixo:

Tabela 1: Documentos normativos que respaldam a Política de Inclusão escolar no município de Valença-BA.

\begin{tabular}{|c|c|c|}
\hline Documentos & Escopo & Dados analisados \\
\hline $\begin{array}{l}\text { Constituição } \\
\text { Federal } \\
\text { (Brasil, 1988) }\end{array}$ & $\begin{array}{l}\text { Garantia dos direitos e deveres } \\
\text { individuais e sociais. }\end{array}$ & $\begin{array}{l}\text { Educação básica em } \\
\text { âmbito Federal }\end{array}$ \\
\hline $\begin{array}{lr}\text { LDBN } & \text { Lei } \quad \mathrm{n}^{\circ} \\
9394 / 96 & \text { (Brasil, } \\
1988) & \end{array}$ & $\begin{array}{l}\text { Estabelece as diretrizes e bases da } \\
\text { educação nacional. }\end{array}$ & $\begin{array}{l}\text { Educação básica } \\
\text { âmbito Federal }\end{array}$ \\
\hline $\begin{array}{l}\text { Plano Nacional de } \\
\text { Educação (Brasil, } \\
\text { 2014) }\end{array}$ & $\begin{array}{l}\text { Define políticas públicas e orienta as } \\
\text { ações educacionais em âmbito nacional } \\
\text { com projeção para dez anos. }\end{array}$ & $\begin{array}{l}\text { Educação básica } \\
\text { âmbito Federal }\end{array}$ \\
\hline $\begin{array}{l}\text { Plano Estadual de } \\
\text { Educação (Bahia, } \\
\text { 2016) }\end{array}$ & $\begin{array}{l}\text { Define políticas públicas e orienta as } \\
\text { ações educacionais em âmbito estadual } \\
\text { com projeção para dez anos. }\end{array}$ & $\begin{array}{l}\text { Educação básica } \\
\text { âmbito Estadual }\end{array}$ \\
\hline $\begin{array}{l}\text { Plano Municipal de } \\
\text { Valença (Valença, } \\
\text { 2015) }\end{array}$ & $\begin{array}{l}\text { Define políticas públicas e orienta as } \\
\text { ações educacionais no âmbito municipal } \\
\text { com projeção para dez anos }\end{array}$ & $\begin{array}{l}\text { Educação básica } \\
\text { âmbito municipal }\end{array}$ \\
\hline $\begin{array}{l}\text { Política Nacional de } \\
\text { Educação Inclusiva } \\
\text { (Brasil, 2008) }\end{array}$ & $\begin{array}{l}\text { Visa constituir políticas públicas } \\
\text { promotoras de uma educação de } \\
\text { qualidade para todos os estudantes. }\end{array}$ & $\begin{array}{l}\text { Educação básica } \\
\text { âmbito Federal }\end{array}$ \\
\hline $\begin{array}{l}\text { Lei no 13.146/15) } \\
\text { (Brasil, 2015) }\end{array}$ & $\begin{array}{l}\text { Dispõe sobre os princípios normativos } \\
\text { que garantem o direito a educação e } \\
\text { outras especificidades a pessoas com } \\
\text { deficiência. }\end{array}$ & $\begin{array}{l}\text { Educação básica } \\
\text { âmbito Federal }\end{array}$ \\
\hline
\end{tabular}

Fonte: Autores (2020)

No art. 5 da Lei de Diretrizes e Bases da Educação - LDB lei no 9394/96 (BRASIL, 1996) destaca que o acesso à educação básica obrigatória é direito público subjetivo, podendo qualquer cidadão, grupo de cidadãos, associação comunitária, organização sindical, entidade de classe ou outra legalmente constituída e, ainda, o Ministério Público, acionar o poder público para exigi-lo.

A nossa Constituição Federal no artigo 205, assegura a Educação como um direito de todos, sendo dever do Estado e da família prover condições de acesso e papel da sociedade promover e incentivar a Educação visando o pleno desenvolvimento da pessoa, seu preparo para o exercício da cidadania e qualificação para o trabalho (BRASIL, 1988). 
Revista Multidisciplinar do Nordeste Mineiro,

\section{$2021 / 01$}

ISSN 2178-6925

A democratização e universalização da Educação de qualidade está em evidencia nas legislações brasileiras, reforçando a equidade. Desta forma, compreende-se a política de Inclusão escolar como produtos da interação entre o governo (União, Estados, Municípios), os diversos sujeitos educacionais (família, professores, gestores, funcionários de apoio) e a sociedade. Para que estas políticas educacionais sejam efetivadas em âmbito educacional, o envolvimento destes é de suma importância.

A União em parceria com os Estados e Municípios definem as políticas públicas e orientam as ações educacionais em âmbito nacional com projeção para dez anos o processo de concepção e elaboração dos Planos educacionais pontuam o contexto administrativo educacional no Brasil, buscando resultados positivos das políticas públicas a cada 10 anos tendo como principal proposta a universalização escolar, bem como o alcance de metas que preconizam a inclusão escolar.

No âmbito das políticas públicas educacionais está a Educação Inclusiva que foram pensadas e elaboradas no intuito de qualificar os espaços regulares de ensino para o atendimento de todos os alunos, privilegiando a diversidade, promovendo assim, a transformação do cenário escolar (RODRIGUES et al., 2017).

Para Andrade e Damasceno (2017):

As Políticas inclusivas possuem o intuito de transformar o cenário escolar, de modo que proclamam avanços em prol de uma escola acolhedora, afirmando a possibilidade da educação da pessoa com deficiência em classes e escolas regulares. Logo, notamos que a inclusão escolar passa a ser fundamental para se viver uma educação democrática (ANDRADE; DAMASCENO, 2017, p. 206).

A política de Inclusão no Brasil determina que a Educação de qualidade e equitativa seja oferecida a todos os alunos dentro do mesmo contexto escolar, participando das mesmas atividades comuns, ainda que adaptadas para atender a diversidade e a heterogeneidade destes sujeitos, fazendo valer o direito educacional de todos. Todavia, é de suma importância e necessário "universalizá-la e melhorar sua qualidade, bem como tomar medidas efetivas para reduzir as desigualdades" (UNESCO, 1990, p. 04). 
Revista Multidisciplinar do Nordeste Mineiro,

\section{1/01}

ISSN 2178-6925

A Constituição Federal (BRASIL, 1988) no seu art. 206, § I, estabelece a igualdade de condições de acesso e permanência na escola, bem como o pluralismo de ideias e de concepções pedagógicas e reforça no art. 208 essa concepção como sendo parte dos princípios democráticos para o ensino de qualidade, gratuito, equitativo e igualitário para todos, preferencialmente na rede regular de ensino, sendo dever do Estado a garantia desses direitos.

Em consonância com a Constituição, a Lei de Diretrizes e Bases da Educação - LDB lei № 9394/96 (BRASIL, 1996) em seu art. 3ํp preconiza que o ensino deve ser ministrado com base nos princípios de igualdade de condições de acesso e permanência na escola, liberdade de aprender, ensinar, gratuidade do ensino público, embora promova a coexistência de instituições públicas e privadas de ensino, garantia de padrão de qualidade e do direito à educação e à aprendizagem ao longo da vida.

$O$ art. 59 de LDB preconiza ainda que os sistemas de ensino devem assegurar aos alunos currículo, métodos, recursos e organização específicos para atender às suas necessidades. E define também, dentre as normas para a organização da educação básica, no art. 37 as "[...] oportunidades educacionais apropriadas, consideradas as características do alunado, seus interesses, condições de vida e de trabalho, mediante cursos e exames" (BRASIL, 1996, p.31).

A respeito da universalização, o Plano Nacional de Educação - PNE, lei 10.172/2001 destaca que esse se constitui como um grande avanço para a Educação, sobretudo na garantia do atendimento à diversidade humana, pois esta política reconhece a pertinência do acesso de todos a Educação de qualidade e que todos aprendam no mesmo contexto educacional. Assim, ao estabelecer objetivos e metas, este dispositivo legal aponta um déficit referente à oferta de matrículas para alunos com deficiência nas classes comuns do ensino regular, à formação docente, à acessibilidade física e ao atendimento educacional especializado, enfim, a superação do paradigma da exclusão e da segregação.

[...] a educação inclusiva assume espaço central no debate acerca da sociedade contemporânea e do papel da escola na superação da lógica da exclusão. A partir dos referenciais para a construção de sistemas educacionais inclusivos, a organização de escolas e classes especiais passa a ser repensada, implicando uma mudança estrutural e cultural da 
Revista Multidisciplinar do Nordeste Mineiro,

\section{1/01}

ISSN 2178-6925

escola para que todos os alunos tenham suas especificidades atendidas. (BRASIL, 2008, p. 05).

A Lei n 13.005/2014, que aprova o Plano Nacional de Educação - PNE e dá outras providências. A referida lei prevê em suas diretrizes a melhoria da qualidade da educação, formação para o trabalho e para a cidadania, com ênfase nos valores morais e éticos em que se fundamenta a sociedade, promoção do princípio da gestão democrática da educação pública, bem como o estabelecimento de meta de aplicação de recursos públicos em educação como proporção do Produto Interno Bruto (PIB), que assegure atendimento às necessidades de expansão, com padrão de qualidade e equidade; promoção dos princípios do respeito aos direitos humanos, à diversidade, entre outros (BRASIL, 2014).

De acordo com Dourado (2016), a lei ำ 13005/14 determina diretrizes, metas e estratégias para as políticas educacionais no decênio 2014-2024. As 20 metas definidas pela lei do PNE relevam os principais desafios para as políticas públicas brasileiras e oferecem direções para as quais as ações dos entes federativos devem convergir, com a finalidade de consolidar um sistema educacional de qualidade.

Impulsionando a inclusão educacional e social, o Decreto ํㅡ 5.296/04 regulamentou as leis $n^{\circ}=10.048 / 00$ e № 10.098/00, estabelecendo normas e critérios para a promoção da acessibilidade às pessoas com deficiência ou com mobilidade reduzida. Nesse mesmo caminho é aprovado em 2002 a Lei ㄲo 10.436/02 que reconhece a Língua Brasileira de Sinais como meio legal de comunicação e expressão, determinando que sejam garantidas formas institucionalizadas de apoiar seu uso e difusão, bem como a inclusão da disciplina de Libras como parte integrante do currículo nos cursos de formação de professores e de fonoaudiologia (BRASIL, 2008).

O Programa de apoio à formação Superior e licenciatura interculturais indígenas - PROLIND, também é uma política pública voltada à para a formação de professores indígenas para o exercício da docência nas escolas indígenas, que integrem ensino, pesquisa e extensão e promovam a valorização do estudo em temas como línguas maternas, gestão e sustentabilidade das terras e culturas dos povos indígenas (BRASIL, 2019). 
Revista Multidisciplinar do Nordeste Mineiro,

\section{1/01}

ISSN 2178-6925

No município de Valença, apesar da priorização da qualidade de atendimento no sistema Municipal de ensino no tocante às populações campesinas e comunidades quilombolas, as metas lançadas no plano de 2015-2025 ainda engatinham no que se refere a qualidade da educação e desde o governo passado está se articulando para adequar a Proposta Curricular, de modo a atender as peculiaridades destas comunidades.

O Programa Escola Acessível, criado em 2013 é uma política pública inclusiva que tem como objetivo a promoção das condições de acessibilidade ao ambiente físico, aos recursos didáticos e pedagógicos e à comunicação e informação nas escolas públicas de ensino regular. O Programa disponibiliza recursos, por meio do Programa Dinheiro Direto na Escola - PDDE, às escolas contempladas pelo Programa Implantação de Salas de Recursos Multifuncionais e dá outras providencias (BRASIL, 2013).

Todavia, e, principalmente na Educação Infantil, há uma preocupação na proposta de Inclusão escolar conforme a lei de diretrizes e Bases da Educação brasileira (Lei no 9394/96) e o Plano Municipal em consonância com o que preconiza o Plano Nacional de Educação (PNE) e o Plano Estadual de Educação (PEE). No entanto, o município ainda está aquém do esperado, pois grande parte das instituições públicas não possuem estrutura física adequada que respeite as exigências normativas Educacionais de Inclusão. Por outro lado, o número de alunos por professor nas turmas de Berçário das instituições públicas de Educação Infantil é alto em comparação com as demais instituições (01 professor para 06 a 08 bebês de 0 a 2 anos).

No que se refere à educação de crianças com necessidades especiais, 0 atendimento é realizado nas instituições públicas em parceria com a Associação de Amigos do Autismo (AMA) e a sala de recursos multifuncionais (SRM). No entanto, há uma grande dificuldade da sala multifuncional em atender essas crianças, visto que esse ambiente possui estrutura física e humana adequada, mas não atende à demanda necessária, de acordo com a lei de acessibilidade - Decreto Lei 5296 e a formação continuada dos profissionais, o que dificulta ainda mais fomentar e realizar um trabalho de qualidade (VALENÇA, 2015). 
Revista Multidisciplinar do Nordeste Mineiro,

\section{1/01}

ISSN 2178-6925

No que se refere ao Ensino Fundamental, o Município oferece o Ensino Fundamental na perspectiva do Ensino Regular e na modalidade da Educação de Jovens e Adultos, em sistema de aceleração da aprendizagem, com vistas a garantir àqueles que não conseguiram concluir os estudos na idade apropriada assim fazê-lo, conforme estabelece a legislação nacional, estadual e municipal.

De acordo com o Plano Municipal, Valença, possui ainda um alto índice de defasagem idade-série no ensino regular, conforme os dados estatísticos dos últimos anos, e não possui nenhuma política ou projeto que se articule no embate a esse problema, existem ações isoladas, gerenciadas pelas próprias instituições e acompanhadas pela secretaria de educação.

O Plano Municipal de Educação (PME) ainda destaca que a oferta da modalidade da Educação de Jovens e Adultos, através da perspectiva de aceleração da aprendizagem, ofertadas no Ensino Noturno, também sofre com altos índices de evasão e repetência. Infelizmente, durante o último decênio, mesmo com a existência de vários programas educacionais de inclusão, o município de Valença ainda apresenta uma demanda significativa de crianças, jovens e adultos fora da escola, tanto na cidade quanto no campo. É um desafio que precisa ser encarado com bastante seriedade por todos os envolvidos nesse processo.

Vale destacar que o Plano Municipal de educação está em consonância com o inciso $1^{\circ}$ do Plano Estadual de Educação que promulga o "fortalecimento de colaboração entre o Estado e os municípios, inclusive, mediante a adoção de arranjos institucionais, considerando o enlace entre educação, território e desenvolvimento e o compartilhamento de competências políticas, técnicas e financeiras, na perspectiva de um sistema nacional de educação (BAHIA, 2016).

Outra política educacional que merece destaque, é a lei oํ 11.494/2007 que regulamenta o Fundo de Manutenção e Desenvolvimento da Educação Básica e de Valorização dos Profissionais da Educação (FUNDEB). Os Fundos destinam-se à manutenção e ao desenvolvimento da educação básica pública e à valorização dos trabalhadores em educação, incluindo sua condigna remuneração, observado o disposto nesta Lei (BRASIL, 2007). 
Revista Multidisciplinar do Nordeste Mineiro,

\section{1/01}

ISSN 2178-6925

O FUNDEB fixa em seu $\S 2^{\circ}$ que as instituições de ensino que ofertam a Educação básica, devem obrigatoriamente "oferecer igualdade de condições para o acesso e permanência na escola e atendimento educacional gratuito a todos os seus alunos", bem como atender a padrões mínimos de qualidade definidos pelo órgão normativo do sistema de ensino, inclusive, obrigatoriamente, ter aprovados seus projetos pedagógicos.

Para respaldo das políticas públicas elencadas acima, outros dispositivos legais foram criados para atender as demandas educacionais e subsidiam a Educação inclusiva como o decreto $\mathrm{n}^{\circ}$ 5626/05 que regulamenta as leis $\mathrm{n} \times 10.048$ e 10. 098/94; e 10. 436/02 com ênfase na promoção da acessibilidade e educação de surdos. A resolução CD/FNDE № 45/2013 que regulamenta o programa de governo "caminhos da escola" que auxiliam alunos que moram em áreas rurais e ribeirinhas. A lei $n$ ำ12. 513/2011 que institui o PRONATEC - Programa Nacional de acesso ao Ensino Técnico e Emprego. A resolução CNE/CEB nํㅜ 02/2010 e o decreto no 7.626/2011 que dispõe sobre a oferta de Educação em âmbito prisional. A resolução n 25/2018 que dispõe sobre recursos financeiros para a EJA.

As políticas públicas em análise apontaram que a Educação Inclusiva tem como objetivo conceitual a promoção do respeito a diversidade na escola, onde há a predileção de apenas um grupo, mas sim, propõe que todos tenham os mesmos direitos a terem uma escolarização em turmas comum, preferencialmente na rede regular de ensino.

Desse modo, de acordo com Mantoan (2003), as escolas inclusivas propõem um modo de se constituir o sistema educacional que considera as necessidades de todos os alunos e que é estruturado em função dessas necessidades. Nesse sentido, a inclusão é o agente transformador da perspectiva educacional, pois não se trata apenas de ajudar somente alunos com dificuldade na escola, mas no sentido de apoiar a todos sem exceção.

Nesse sentido, a perspectiva inclusiva trazida nos documentos normativos oficiais tanto em âmbito municipal quanto em âmbito Estadual e Federal, valoriza a diversidade humana e busca a pluralidade étnica, cultural e intelectual que são 
Revista Multidisciplinar do Nordeste Mineiro,

\section{$2021 / 01$}

ISSN 2178-6925

inerentes aos seres humanos, promovendo a aprendizagem de todos, sem exceção.

Vale destacar que o ato de incluir é o saldo positivo de uma dívida histórica que o Brasil tem com as minorias. Antes de tudo é uma lição de cidadania, de equidade, de respeito a diversidade. A Inclusão é o reconhecimento de que todos merecem e precisam participar de um aprendizado pleno e significativo independentemente de suas diferenças. "Para uma sociedade efetivamente democrática, na qual todos tenham uma vida decente, é preciso fazer da inclusão escolar uma realidade" (SILVA NETO et al., 2018, p. 91).

\section{CONSIDERAÇÕES FINAIS}

Tendo em vista a política de inclusão educacional atual, discorrer acerca do direito à educação para as minorias requer a revisão do conceito de democracia e sua articulação na forma como configura as políticas públicas educacionais no Brasil. Vale salientar que não se pode falar sobre equiparação de oportunidades e inclusão, sem incluir a questão da diversidade no tocante a afirmação da igualdade.

Assim, o estudo apontou que a cidade de Valença-BA enfrenta ainda muitos desafios no que se refere a efetividade das políticas de inclusão educacional, todavia, verifica-se que o Munícipio tem evoluído, ainda que de forma gradual no cumprimento e manutenção das normativas educacionais preconizadas na Constituição Federal de 1988, na LDBN lei no 9394/96 e os demais documentos normativos em âmbitos Federais, Estaduais e Municipais.

O estudo apontou também a necessidade de pesquisas direcionadas as políticas de Inclusão destinado não apenas a um grupo exclusivo de alunos, o dos deficientes, mas especializada no aluno e dedicada à pesquisa e ao desenvolvimento de novas maneiras de se ensinar, adequadas à diversidade dos aprendizes e que estejam compatíveis com os ideais democráticos de uma educação para todos, promulgados pela nossa Constituição. 
Revista Multidisciplinar do Nordeste Mineiro,

$2021 / 01$

ISSN 2178-6925

\section{REFERÊNCIAS}

ANDRADE, P. F.; DAMASCENO, A. R. Políticas públicas de educação inclusiva: reflexões acerca da educação e da sociedade à luz da Teoria Crítica. Textura Canoas v. 19 n.39 p. 201-220 jan./abr. 2017. Disponível em:

http://www.periodicos.ulbra.br/index.php/txra/article/view/2083/2038. Acesso em: 29 abr. 2020.

BAHIA, Governo do Estado da. Plano Estadual de Educação 2016-2026.

Secretaria da Educação do Estado da Bahia, 2016. Disponível em:

https://portal.uneb.br/prograd/wp-content/uploads/sites/63/2019/06/lei-pee-ba-

2016.pdf. Acesso em: 28 nov. 2020.

BRASIL, Presidência da República, Casa Civil, Subchefia para Assuntos Jurídicos.

Lei 13.005 de 25 de junho de 2014. Disponível em:

<http://www.jusbrasil.com.br/diarios/72231507/dou-edicao-extra-secao-1-26-06-

2014-pg-1>. Acesso em: 19 mai. 2020.

BRASIL, Ministério da Educação. Documento orientador programa escola acessível. Ministério da Educação. Secretaria de Educação Continuada, Alfabetização, Diversidade e Inclusão. Brasília, Distrito Federal, Brasil. 2013. Disponível em:

http://portal.mec.gov.br/index.php?option=com_docman\&view=download\&alias=132 90-doc-orient2013\&category_slug=junho-2013-pdf\&ltemid=30192 acesso em: 19 mai. 2020.

BRASIL, Ministério da Educação. Lei no 11.494, de 20 de junho de 2007

Regulamenta o Fundo de Manutenção e Desenvolvimento da Educação Básica e de Valorização dos Profissionais da Educação - FUNDEB. Disponível em: http://planodecarreira.mec.gov.br/images/pdf/lei_11494_20062007.pdf. Acesso em: 19 mai. 2020.

BRASIL, Ministério da Educação. Plano Nacional de Educação 2014-2024 [recurso eletrônico] : Lei no 13.005 , de 25 de junho de 2014, que aprova o Plano Nacional de Educação (PNE) e dá outras providências. - Brasília : Câmara dos Deputados, Edições Câmara, 2014. 86 p. - (Série legislação; n. 125). Disponível em: http://www.proec.ufpr.br/download/extensao/2016/creditacao/PNE\%2020142024.pdf. Acesso em: 28 nov. 2020.

BRASIL, Ministério da Educação. Política de Educação Especial na Perspectiva da Educação Inclusiva. Documento elaborado pelo Grupo de Trabalho nomeado pela Portaria no 555/2007, prorrogada pela Portaria n 948/2007, entregue ao 
Revista Multidisciplinar do Nordeste Mineiro,

\section{$2021 / 01$}

ISSN 2178-6925

Ministro da Educação em 07 de janeiro de 2008. Disponível em:

http://portal.mec.gov.br/arquivos/pdf/politicaeducespecial.pdf. Acesso em: 19 mai. 2020.

BRASIL, Ministério da Educação. Programa de Apoio à Formação Superior e Licenciaturas Interculturais Indígenas - PROLIND. Publicado em 2019.

Disponível em: http://portal.mec.gov.br/par/194-secretarias-112877938/secadeducacao-continuada-223369541/17445-programa-de-apoio-a-formacao-superiore-licenciaturas-interculturais-indigenas-prolind-novo. Acesso em: 19 mai. 2020.

BRASIL, Presidência da República, Casa Civil, Subchefia para Assuntos Jurídicos. LDB: Lei de Diretrizes e Bases da Educação Nacional. - 3. ed. - Brasília: Senado Federal, Coordenação de Edições Técnicas, 2019. Disponível em: https://www2.senado.leg.br/bdsf/bitstream/handle/id/559748/lei_de_diretrizes_e_ba ses_3ed.pdf. Acesso em: 19 mai. 2020.

BRASIL, Presidência da República, Casa Civil, Subchefia para Assuntos Jurídicos. Lei Federal 13.146/15. Lei Brasileira de Inclusão. Disponível em: http://www.planalto.gov.br/ccivil_03/_Ato2015-2018/2015/Lei/L13146.htm.

Acesso em: 19 mai. 2020.

BRASIL, Presidência da República, Casa Civil, Subchefia para Assuntos Jurídicos. Constituição da República Federativa do Brasil: texto constitucional promulgado em 5 de outubro de 1988, compilado até a Emenda Constitucional no 105/2019. Brasília: Senado Federal, Coordenação de Edições Técnicas, 2020. 397 p. disponível em:

https://www2.senado.leg.br/bdsf/bitstream/handle/id/566968/CF88_EC105_livro.pdf. Acesso em: 19 mai. 2020.

DOURADO, L. F. Plano Nacional de Educação: política de Estado para a educação brasileira. Brasília: Instituto Nacional de Estudos e Pesquisas Educacionais Anísio Teixeira, 2016. 48 p. -- (PNE em Movimento, ISSN 2448-4288; 1) doi: 10.24109/2448-4296.seriepne.2016.1.

FONSECA, J. J. S. Metodologia da pesquisa científica. Fortaleza: UEC, 2002. Apostila.

MANTOAN, M. T. E. Integração x Inclusão: Escola (de qualidade) para todos. Universidade Estadual de Campinas - Faculdade de Educação, 2003. Disponível em: http://www.lite.fe.unicamp.br/papet/2003/ep403/integracao_x_inclusao.htm. Acesso em: 29 abr. 2020.

RODRIGUES, J. M. C.; et al. Políticas públicas de educação no brasil: fracasso escolar, culpabilização dos alunos e inocentização da escola Janine. Revista on Line de Política e Gestão Educacional, 979-1015. v. 21, n. esp. 2, nov./2017. Disponível em: https://periodicos.fclar.unesp.br/rpge/article/view/10372. Acesso em: 19 mai. 2020. 
Revista Multidisciplinar do Nordeste Mineiro,

\section{1/01}

ISSN 2178-6925

SILVA NETO, A. O.; et al. Educação inclusiva: uma escola para todos. Revista Educação Especial. v. 31, n. 60, p. 81-92 | jan./mar. 2018 Santa Maria. Disponível em: https://periodicos.ufsm.br/educacaoespecial

http://dx.doi.org/10.5902/1984686X24091. Acesso em: 05 mai. 2020.

UNESCO, Declaração Mundial de Educação para Todos. Jomtien, Tailândia, 1990.

VALENÇA, Prefeitura Municipal de. Plano Municipal de Educação 2015-2025.

Secretaria Municipal de Educação. 3 - Ano VII - № 1328: 22 de jun. de 2015.

Disponível em: https://sai.io.org.br/ba/valenca/site. Acesso em: 28 nov. 2020. 